\title{
Decision analysis to guide recovery of the po'ouli, a critically endangered Hawaiian honeycreeper
}

\author{
Eric A. VanderWerf ${ }^{a, *}$, Jim J. Groombridge ${ }^{b, 1}$, J. Scott Fretz $^{c}$, Kirsty J. Swinnerton ${ }^{b}$ \\ ${ }^{\mathrm{a}}$ US Fish and Wildlife Service, 300 Ala Moana Blud, Rm 3-122, Box 50088, Honolulu, HI 96850, USA \\ ${ }^{\mathrm{b}}$ Maui Forest Bird Recovery Project, 2465 Olinda Road, Makawao, HI 96768, USA \\ ${ }^{c}$ Hawai'i Division of Forestry and Wildlife, 1151 Punchbowl Street, Room 325, Honolulu, HI 96813, USA
}

\section{A R T I C L E I N F O}

\section{Article history:}

Received 9 August 2005

Received in revised form

8 November 2005

Accepted 13 November 2005

\section{Keywords:}

Decision tree

Endangered species recovery

Hawaii

Po'ouli

Structured decision analysis

\begin{abstract}
A B S T R A C T
We used a probabilistic decision tree to help select among alternative recovery strategies for the Po'ouli, a critically endangered forest bird endemic to the Hawaiian island of Maui. The Po'ouli is one of the rarest birds in the world, with only three individuals known, and no breeding pairs. The most urgent conservation need for the species is to create a breeding pair and obtain eggs for captive propagation. Seven recovery strategies had been proposed, and there was disagreement among conservation workers about which strategy to pursue. In addition to lengthy discussions, a decision tree was introduced to provide an objective way of quantifying the chance of success under each alternative. All available information was used to attempt evaluation of each node in the decision tree. The overall chance of obtaining eggs was calculated by multiplying estimates at each node under each alternative. All options produced low estimates of potential success, but two options, removal of all birds to captivity and placement of the birds in a field aviary in an accessible location, produced similar estimates of success. The US Fish and Wildlife Service and the Hawaii Division of Forestry and Wildlife eventually agreed that removal to captivity was the preferred alternative because it could be implemented quickly, which was important considering the advanced age of the birds, and would make it easier to provide veterinary care and ensure their safety from predators, severe weather, and vandals. Decision trees and other structured models should not be relied on exclusively, but they can provide an objective method of helping to make difficult conservation decisions and provide a record of complex thought processes used in reaching a determination. The case of the Po'ouli may serve as a template for navigation towards a decision to recover other species of extreme rarity.
\end{abstract}

(c) 2005 Elsevier Ltd. All rights reserved.

\section{Introduction}

A dilemma familiar to all managers who must make recovery decisions for critically endangered species is the uncertainty of different management outcomes (Burgman et al., 1993;
Drechsler, 2000; Harwood, 2000). Choosing the best alternative often involves consideration of less than perfect biological information, sometimes conflicting expert opinions, and abiotic factors such as financial cost and political preference. It can be difficult to combine this information in a straightfor-

\footnotetext{
* Corresponding author: Tel.: +1 808792 9461; fax: +1 8087929580.

E-mail address: eric_vanderwerf@fws.gov (E.A. VanderWerf).

${ }^{1}$ Present Address: Durrell Institute of Conservation and Ecology, University of Kent, Canterbury CT2 7NZ, UK. 0006-3207/\$ - see front matter @ 2005 Elsevier Ltd. All rights reserved. doi:10.1016/j.biocon.2005.11.005
} 
ward and transparent way. Structured decision analysis provides various frameworks that can help resolve difficult issues by characterizing uncertainty about possible outcomes, and by estimating probabilities of success for alternative actions based on the best available information (Starfield and Bleloch, 1991; Burgman et al., 1993; Drechsler, 2000; Haight et al., 2000; Tenhumberg et al., 2004). The framework applied most often in conservation biology is the decision tree, which was first used by Thibodeau (1983), and subsequently developed by Maguire (1986) to help managers navigate to a decision in a consistent and explicit manner. Decision trees can be designed to fit many different situations, and are often the most appropriate tool when there is a single objective and stochastic variation is present in the system (Starfield and Bleloch, 1991).

This paper illustrates how a decision tree was used to evaluate alternative recovery strategies for a critically endangered Hawaiian forest bird called the Po'ouli (Melamprosops phaeosoma). Similar processes have been conducted for other endangered species (Maguire et al., 1987; Drechsler et al., 1998; Drechsler, 2000; Haight et al., 2000), and may be useful in future decisions, such as choosing the best conservation tactics for the recently rediscovered Ivory-billed Woodpecker (Campephilus principalis).

\section{Background}

The Po'ouli is a critically endangered Hawaiian honeycreeper endemic to the island of Maui, and is one of the rarest birds in the world, with only three known individuals remaining (Groombridge et al., 2004b, but see Epilogue). The Po'ouli was apparently unknown to native Hawaiians and was first discovered in 1973 (Casey and Jacobi, 1974). Morphological and genetic evidence indicate the Po'ouli forms a unique lineage within the Hawaiian honeycreepers, and it comprises a monotypic genus (Fleischer et al., 2001; James, 2004). The Po'ouli was already rare when discovered, and historically it has been known only from a remote 1300 hectare (3200 acre) area of wet montane forest on the northern and eastern slopes of Haleakala volcano on East Maui (Scott et al., 1986; Mountainspring et al., 1990). Fossil evidence indicates Po'ouli once inhabited drier forests at lower elevation on the western slope of Haleakala (James and Olson, 1991). The population was estimated at $140 \pm 280$ birds in the early 1980s (Scott et al., 1986), but estimates were imprecise due to the species' low density and cryptic behavior. The number and range of the Po'ouli declined from 1976 to 1985 , probably due to habitat degradation by feral pigs (Sus scrofa), introduced mosquitoborne diseases, and predation by alien mammals (Mountainspring et al., 1990; Pratt et al., 1997).

Conservation efforts for the Po'ouli have included creation of the 3035-hectare (7500-acre) Hanawi Natural Area Reserve in 1986 to provide additional protection for lands encompassing the known range; fencing of 800 hectares (2000 acres) in the upper portion of Hanawi by 1996 and significant reduction of feral ungulate numbers by 1997 (Bill Evanson, pers. comm.); protection of adjacent forest by Haleakala National Park and formation of the East Maui Watershed Partnership in 1991; and ground-based predator control in the home ranges of the three known birds (Malcolm et al. in litt.). Ecological and life-history research has been carried out by the Maui Forest Bird Recovery Project, under direction of the US Geological Survey Biological Resources Division from 1994 to 1996 (Baker, 2001) and subsequently under direction of the Hawaii Department of Land and Natural Resources and US Fish and Wildlife Service.

The Po'ouli continued to decline despite these conservation efforts, and surveys in 1994-1995 found only six birds at four locations, while surveys from 1997 to 2000 located only three birds (Reynolds and Snetsinger, 2001). No other Po'ouli have been located since these three birds were color-banded in 1997 and 1998 (Maui Forest Bird Recovery Project, unpubl. data). Genetic sexing of the three birds produced conflicting results, but the best available information indicated they consisted of one male and two females (but see Epilogue). These birds occur in non-overlapping home ranges separated by $0.75-1.7 \mathrm{~km}$ at elevations from 1500 to $1950 \mathrm{~m}$ (5000-6500 feet) (Fig. 1; Groombridge et al., in press). The three birds have never been observed together and it is very unlikely any breeding will occur without intervention. Since there are no known breeding pairs and the last known reproduction occurred in 1995 (Reynolds and Snetsinger, 2001), the most urgent conservation need is to facilitate the formation of a breeding pair.

Alternative recovery strategies for the Po'ouli were outlined in 1999 as part of an Environmental Assessment (US Fish and Wildlife Service, Hawaii Department of Land and Natural Resources, 1999). Based on that assesment and on subsequent public comments, it was determined that the preferred alternative at that time was continued habitat management in conjunction with translocation of a female into the home range of the male, in hopes that they would form a breeding pair and nest.

After nearly two years of planning and effort, a female Po'ouli was captured on 4 April 2002 and translocated $2.5 \mathrm{~km}$ on foot into the home range of the male (Groombridge et al., 2004b; Fig. 1). The female was released in the male's home range at dusk and roosted in the male's home range overnight, but the following day she moved back along the translocation route to her own home range, where she remained. Although the translocation effort was unsuccessful in establishing a breeding pair, it demonstrated that the species could be safely manipulated, and the Po'ouli showed positive signs of acclimation to captivity, reacting passively to its holding cage and readily consuming novel food (Groombridge et al., 2004b).

\section{Need for a new strategy}

On 25 June 2002, the Po'ouli Working Group, comprising representatives from the US Fish and Wildlife Service, Hawaii Department of Land and Natural Resources, Maui Forest Bird Recovery Project, Zoological Society of San Diego, and Hawaiian Forest Bird Recovery Team, convened on Maui to discuss the next step in attempting to conserve the Po'ouli. Several alternatives from the 1999 Environmental Assesment were discussed, including another translocation, placing the birds in a field aviary in Hanawi to facilitate pair formation, remov- 


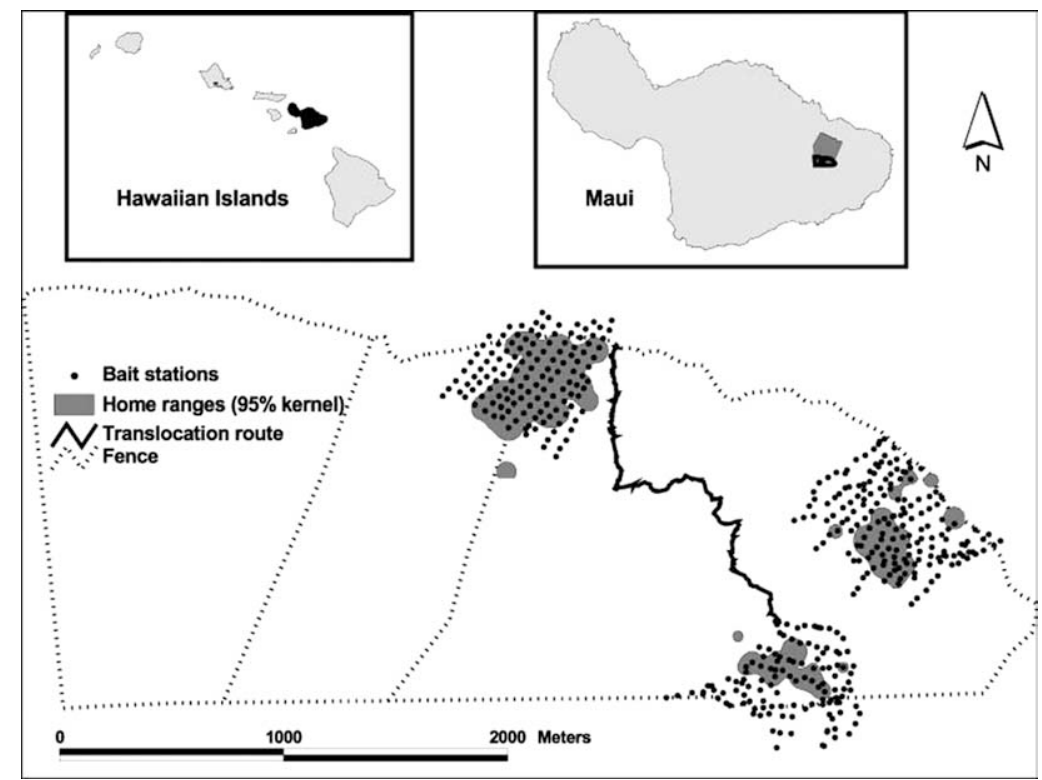

Fig. 1 - Locations of Po'ouli home ranges, boundaries of fenced management units, rodent control bait stations, and the previous translocation route in the State of Hawaii Hanawi Natural Area Reserve in east Maui. Adapted from Groombridge et al. (2004b) by John Vetter, Maui Forest Bird Recovery Project.

ing the birds from the wild to attempt captive propagation, continued habitat management, or no further action. A new alternative was also introduced, which called for the birds to be placed in a field aviary at a more accessible location than Hanawi.

None of the alternatives were universally supported by all members of the group. It was clear that there were serious risks associated with all options, and that the chance of success was low no matter which alternative was chosen. Each alternative had advantages and disadvantages, and strong arguments were made for and against several alternatives. It was agreed that continued habitat management, including maintenance of feral ungulate exclusion fences, control and interdiction of alien weeds, and control of introduced mammalian predators, were integral to all strategies, and that these actions should be continued regardless of which option was chosen. The Po'ouli is relatively specialized in its forag- ing, relying heavily on native snails for food, and destruction by feral pigs of understory vegetation used by snails and other invertebrates is regarded as one of the primary causes of the decline of the Po'ouli (Mountainspring et al., 1990; Pratt et al., 1997). In view of this potential deadlock, a structured decision approach was used to help evaluate and compare the alternatives, including a probabilistic decision tree and other methods, which are described below.

\section{Methods}

We evaluated seven alternative strategies for attempting to recover the Po'ouli (Table 1). The first six were taken from a previous Environmental Assessment (US Fish and Wildlife Service, Hawaii Department of Land and Natural Resources, 1999), the seventh was based on discussions in 2002. The primary recovery goal for the Po'ouli was to facilitate reproduc-

\section{Table 1 - Descriptions of seven alternative strategies for attempting to recover the Po'ouli}

\begin{tabular}{ll} 
Alternative & \multicolumn{1}{c}{ Description } \\
\hline 1 & $\begin{array}{l}\text { No manipulation of wild adult birds; hope for more birds to be found, natural pair formation among the known birds, and } \\
\text { population increase in response to continued habitat management } \\
\text { Repeat the recent translocation, but with the second female } \\
\text { Catch } 2 \text { or } 3 \text { birds and hold them in a field aviary at Hanawi, then release them upon pair-bond formation or at some later } \\
\text { date } \\
\text { Catch } 2 \text { or } 3 \text { birds and facilitate breeding in a field aviary in Hanawi, then manage the aviary nest. First clutch eggs would be } \\
4\end{array} \quad \begin{array}{l}\text { Catch } 2 \text { or } 3 \text { birds and hold in a field aviary to evaluate their acclimation, then remove them to captivity, or release them if } \\
\text { they do not meet specified acclimation criteria }\end{array}$ \\
6 & Catch 2 or 3 birds and remove them from Hanawi to a captive breeding facility \\
7 & Catch 2 or 3 birds and remove them to a field aviary at a more accessible location
\end{tabular}

For more detailed information about each alternative, see US Fish and Wildlife Service, Hawaii Department of Land and Natural Resources, 1999. 
tion among the three known birds. Removal of eggs for captive propagation is widely recognized as the best method of maximizing reproductive output and increasing population size quickly (Kuehler et al., 2001), but not all parties agreed that eggs should be collected for artificial incubation. We therefore evaluated the chance of successful nesting, and whether eggs could be collected for captive rearing (Table 2).

Achieving the goal of obtaining Po'ouli eggs requires successful completion of several intermediate steps, which can be illustrated as nodes in a tree (Fig. 2) and are described below. The overall chance of success can be calculated by multiplying the estimates of success at each node. The chance of success under various options can be compared by entering values for each parameter specific to each option. Some values, such as adult survival, could be estimated with some degree of accuracy based on scientific research about the Po'ouli and other Hawaiian forest birds. Other values, such as the chance of pair formation, were less well known and more subject to variation among people based on their experience. However, even if the accuracy of certain estimates is unknown, the relative values associated with each alternative are still meaningful in helping to select the best strategy. Part of the purpose of this exercise was to help people think about the various steps that are necessary in reaching the final goal, and how to best go about each step.

The goal of the meeting on 25 June 2002 was not to select a new alternative that day, but to discuss the merits of each alternative and outline the process by which the decision would be made. Each member of the working group was provided with materials describing the alternatives, a decision tree diagram (similar to Fig. 2), and a computer spreadsheet to help calculate estimates of success using the decision tree. The spreadsheet facilitated a type of sensitivity analysis through alteration of various estimates to see how much difference was required before one alternative was likely to be better than another. A second evaluation tool was also provided, an evaluation sheet that asked participants to score the likelihood of success under each alternative on a scale from 0 to 5. Finally, each member was asked to complete a recommendation form stating their opinion and reasoning within one week after the meeting. It was emphasized that the probabilistic tree was not the only tool available to help with this decision, and that the results of this or any decision model should not be relied upon exclusively. The group exercise was not considered a voting process in which the option with the most supporters or the highest average probability of success would automatically be chosen, but rather as an objective process designed to gather ideas, provide opportunity for input, and gauge overall support from a variety of stakeholders.

\section{Decision-tree parameters}

\subsection{Translocation}

This parameter estimated the probability that a bird translocated to another home range or to a captive breeding facility would: (a) die, (b) stay put, or (c) return to its own home range. This included only the direct effect of translocation itself, not subsequent survival, which was included in the next param-

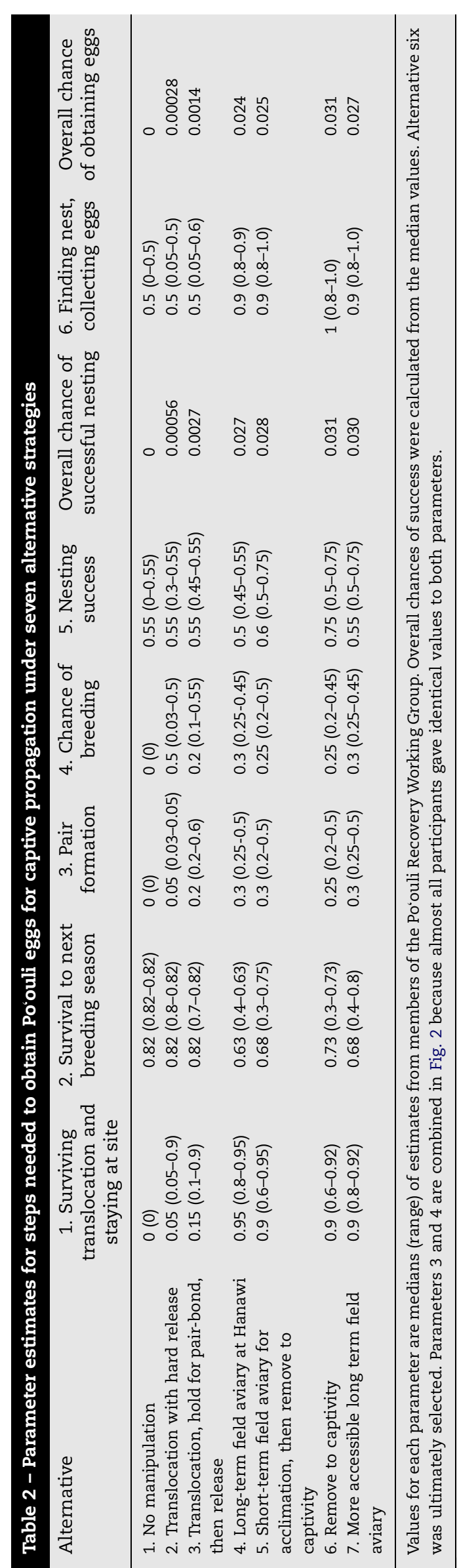




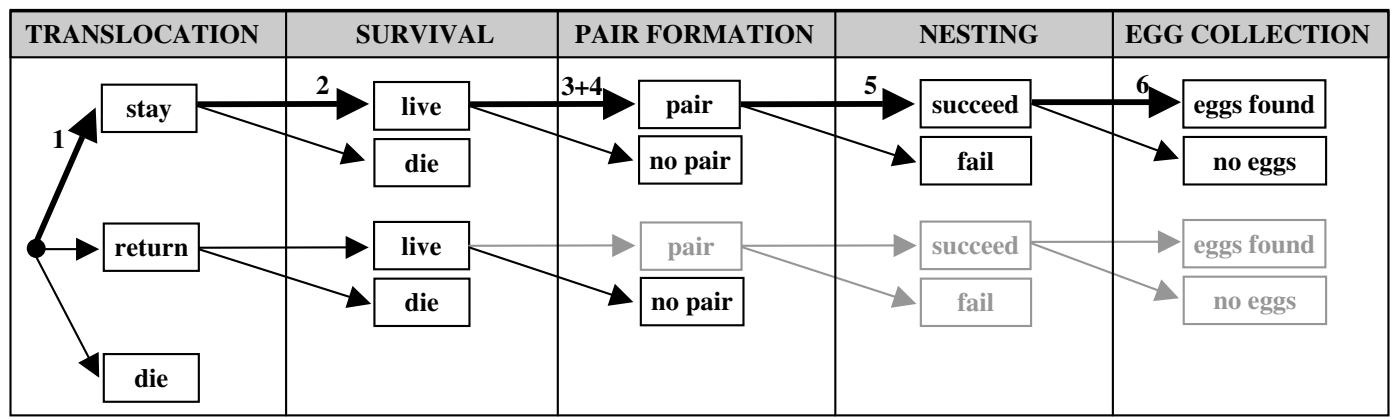

Fig. 2 - Decision tree illustrating the steps that must be completed to obtain Po'ouli eggs for captive propagation. Birds that survive translocation but return to their own home range were deemed very unlikely to form a pair and nest, as indicated by grayed portions of the tree.

eter. Surrogate translocations of Maui Creepers (Paroreomyza montana) did not experience any mortality ( $n=16$; Groombridge et al., 2004a), and translocations of Palila (Loxioides bailleui), Omao (Myadestes obscurus), and Iiwi (Vestiaria coccinea) by four-wheel-drive vehicle or helicopter also experienced little mortality (G. Massey, pers. comm.; J. Nelson, pers. comm.), so the chance of mortality while translocating Po'ouli might be low. However, previous translocations, including that of the Po'ouli, have shown that Hawaiian forest birds have high site fidelity and often return to their own home range (Fancy et al., 1997, 2001; Groombridge et al., 2004a,b), and there was no reason to believe the second female Po'ouli would behave differently. Chances of mortality might be higher during a longer translocation by helicopter than during a shorter translocation carried out on foot. Birds translocated to a captive breeding facility obviously would not have the option of returning to their own home range.

\subsection{Survival}

After translocation, birds must survive to the next breeding season in order to reproduce. The annual survival rate of wild Po'ouli is unknown, but an estimate can be obtained by averaging estimates from studies of other insectivorous Hawaiian forest birds (0.88 for Hawaii Creeper, Oreomystis mana, Woodworth et al., 2001; 0.82 for Hawaii 'Akepa, Loxops c. coccineus, Lepson and Freed, 1997; 0.71 for 'Akiapola'au, Hemignathus munroi, Ralph and Fancy, 1996; 0.87 for Hawaii 'Elepaio (Chasiempis sandwichensis ridgwayi, VanderWerf, 2003; and 0.81 for O‘ahu 'Elepaio, Chasiempis sandwichensis ibidis, VanderWerf and Smith, 2002). Survival of Po'ouli in captivity can be estimated from the results of previous attempts at bringing wild adult Hawaiian forest birds into captivity, yielding an average of 0.73 . These data were provided in Appendix $C$ of the Environmental Assesment and were summarized in a comment letter in Appendix A (US Fish and Wildlife Service, Hawaii Department of Land and Natural Resources, 1999). Survival in a long-term field aviary at Hanawi might be lower than survival in captivity because it might prove difficult to protect birds from exposure during periods of severe weather or to provide them with adequate food or veterinary care. Survival in a long-term field aviary at a more accessible location might be higher than survival at a similar aviary at Hanawi, but there still could be more logistical challenges than if located at a fully equipped captive breeding facility.

\subsection{Pair formation}

The absolute value of this parameter is difficult to estimate, but relative values are still meaningful for distinguishing among the alternatives. Pair formation is often more likely when birds have the opportunity to choose among several prospective mates, but in the case of the Po'ouli little mate selection is possible because so few individuals remain, so the chances of pair formation may be low under all alternatives. In a field aviary or captivity it might be possible to improve the chance of pair formation through song playbacks, gradual introduction, and enriched environments. The more natural setting, temperature, humidity, and light levels in a field aviary might increase the chance of pair formation, but it might be possible to alter these conditions strategically in a captive setting to encourage breeding. Each of the known Po'ouli associate very closely with Maui Parrotbills (Pseudonestor xanthophrys), and one female Po'ouli has been observed feeding parrotbill fledglings (T. Malcolm, pers. comm.). Pair formation could be inhibited by the presence of Maui Parrotbills, and this distraction could be controlled only in ex situ captivity.

\subsection{Probability of breeding}

As with pair formation, this parameter is difficult to estimate. In retrospect, parameters 3 and 4 could have been combined into a single parameter because almost all participants assigned identical values to both parameters, but during initial discussions they were thought to be independent and important enough to warrant separate consideration.

\subsection{Successful breeding}

This parameter measured the probability of the eggs hatching and chicks fledging and not being preyed upon or killed by harsh weather. Only two nests of the Po'ouli have ever been found, both from the same pair, one of which failed and one of which fledged a single offspring (Engilis et al., 1996; Kepler et al., 1996). Because the sample size of Po'ouli nests 
is so small, the nest success rate can be estimated by averaging success rates from studies of other Hawaiian forest birds at Hanawi (0.42 for Maui Parrotbill, Simon et al., 2000; 0.68 for 'Akohekohe, Simon et al., 2001). It is less appropriate to use values from other areas of Hawaii because the weather is often extremely wet at Hanawi and rainstorms were the most common cause of nest failure (Simon et al., 2001). The success rate in captivity likely would be higher than that in the wild, particularly if eggs were collected for artificial rearing, because there presumably would be no failure due to predation or severe weather. Alternatively, if parent-rearing were permitted, birds might feel more comfortable and might exhibit more normal parental behavior.

\subsection{Chances of finding the nest and collecting eggs}

The chances of finding a nest and collecting eggs or young are lowest in the wild. The steep terrain and dense vegetation at Hanawi make nests difficult to find, and many trees would be unsafe to climb. Nesting behavior might not be readily visible in a field aviary depending on its size, and a nest could fail due to bad weather before the eggs were collected.

\section{Additional factors}

The biological factors described above were used to help arrive at the best potential recovery strategy, but additional practical considerations can affect successful implementation of a preferred alternative. These factors were not included in the decision tree, but they could influence selection of alternatives otherwise thought to have similar chances of success.

\subsection{Ecosystem health}

Hanawi contains some of the least disturbed native forest in Hawaii and supports numerous rare species of plants and animals. Conducting work there has some potential to damage the environment, and this must be weighed against the benefits for Po'ouli (US Fish and Wildlife Service, Hawaii Department of Land and Natural Resources, 1999). Construction of a field aviary would impact a small area of forest, but the impact presumably would be reversible once the aviary was removed. A more serious long-term threat to ecosystem health is the introduction of invasive alien species, which are one of the greatest threats to native ecosystems and species in Hawaii (Stone and Stone, 1989; van Riper and Scott, 2001). Increased traffic into Hanawi, especially bringing in materials for constructing a field aviary, would increase the chance of introducing alien plants and animals that could degrade habitat quality.

\subsection{Feasibility}

Ideally, conservation decisions should not be based on how difficult a task might be, but in reality the feasibility of implementing management actions quickly can affect their efficacy. Moreover, if two alternatives are thought to be similar in their chances of success, but one can be implemented more quickly or economically, then that alternative would be favored. Translocation with hard release or removal of birds to captivity would not require new equipment, facilities, or staff. Translocation with soft release would require construction of a temporary field aviary and additional staff field time. A long-term field aviary at Hanawi or another site would require purchase or construction of a larger aviary and the continual presence of a field crew to ensure the safety of the birds. Care of captive Po'ouli would be a labor-intensive task, and the workload would be greater in an off-site field aviary. If the chosen option involved construction or hiring of additional staff, it could delay implementation.

\subsection{Cryogenic preservation and cell culture}

If all attempts to facilitate reproduction among the existing Po'ouli fail, it might be possible to conserve the species in the future by cloning birds from cell cultures and/or cryogenically preserved tissue. The technology and means for cloning birds may become available soon, and collecting samples that can be preserved until that time is a potential long term conservation strategy (Ryder, 2002). However, in order for such samples to be viable they must be collected very shortly following the bird's death, which probably would be possible only in a captive setting. There is little hope of finding the body of a small Passerine bird in the wild, and in a field aviary it could be difficult to collect samples and transport them to appropriate facilities for preservation before they were excessively degraded.

\section{Results}

Written statements with a recommendation and justification for selection of a particular alternative were received from 17 members of the Po'ouli Recovery Working Group. Thirteen group members also submitted parameterized decision trees as part of their justification. There was much variation in the estimates given by group members for individual parameters (Table 2). In some cases all participants gave the same estimate, such as survival under no manipulation, while in other cases there was general agreement with a few outlying values, such as surviving and remaining at a translocation site following hard release. The chances of success calculated from the values provided were generally low under all alternatives, indicating everyone realized the effort was unlikely to succeed (Fig. 3). Moreover, the wide variation in estimates of individual parameters resulted in overlap of the potential chance of success among several alternatives.

Alternative 6 , removal to a captive breeding facility received the most support and was recommended by 11 participants, but alternative 5, a short-term field aviary for acclimation followed by to removal to captivity, was recommended by 3 participants, and alternative 7, a more accessible long-term field aviary was recommended by 2 participants. Nobody favored alternative 2, a second translocation, or alternative 1, no manipulation. One person recommended a mix of alternatives 3 and 4; capture and management of individuals in a field aviary in Hanawi, and subsequently either manipulation of any eggs produced and their possible removal to ex 


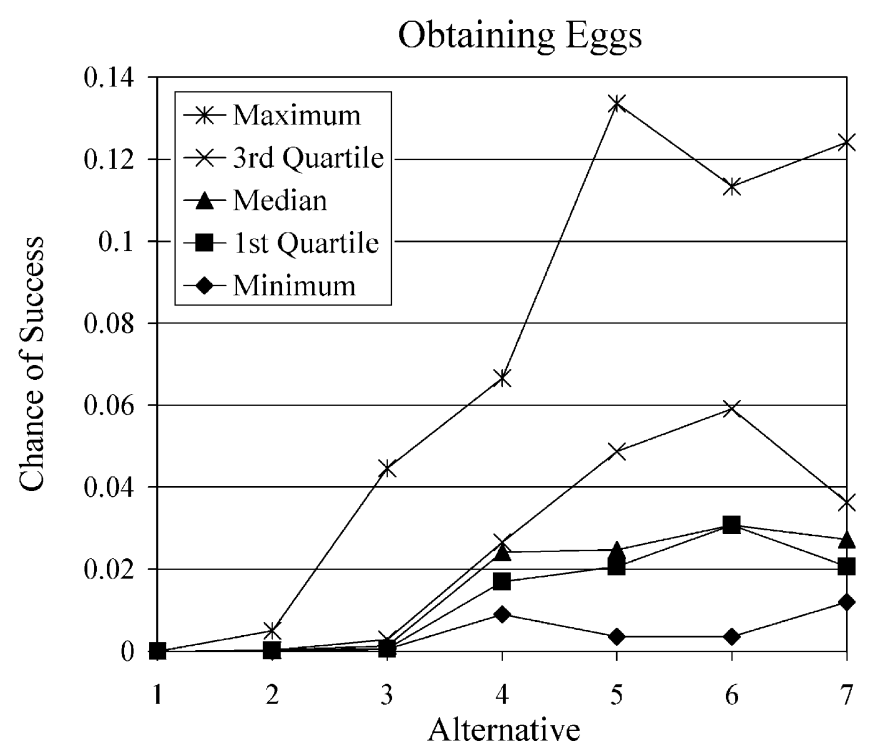

Fig. 3 - Variation in estimates of chance of success (defined as obtaining eggs for captive propagation) under seven alternative strategies for recovering the Po'ouli. Alternative 6 was eventually selected.

situ captivity for rearing, or release of the captured adult birds if the field initiative was deemed unsuccessful. Recommendations were compiled by the Maui Forest Bird Recovery Project and US Fish and Wildlife Service, and summaries of the results were distributed to all group members.

\section{Discussion}

Selecting a recovery strategy for the Po'ouli was extremely difficult. Each alternative had advantages and disadvantages, there was no clear consensus, and strong arguments were made for and against several alternatives. The options that appeared to have the highest probability of facilitating successful nesting and production of eggs for captive propagation were removal of all three birds to captivity, possibly preceded by short-term field acclimation, or placement of the birds in a field aviary in a more accessible location. After reviewing the recommendations submitted by members of the working group, much internal discussion took place within and between the US Fish and Wildlife Service and the Hawaii Department of Land and Natural Resources, the two agencies mandated to recovery endangered species in Hawaii. Both agencies eventually agreed in selecting removal to captivity as the option that offered the best, albeit small, chance for success. The factors ultimately favoring this option were that removal to captivity could be implemented more quickly because a captive breeding facility already existed and was staffed, which was considered important given the advanced age of the three birds, and that it would be more difficult to provide adequate veterinary care in a field aviary and ensure the safety of the birds from predators, severe weather, and vandals.

In a letter to the US Fish and Wildlife Service and Hawaii Department of Land and Natural Resources dated September 26, 2002, the Zoological Society of San Diego expressed with reservations that they would undertake the difficult task of attempting to manage and breed the Po'ouli in captivity. Other captive breeding programs for Hawaiian forest birds operated by the Zoological Society of San Diego have been successful (Kuehler et al., 2000, 2001), but establishing a viable breeding program from just one pair of birds would be the ultimate avicultural challenge.

The remaining alternatives still have merit, and one or more of these could still be implemented in the future. If the birds do not breed in captivity, they could be moved to a field aviary or released back into the wild following pair-bond formation. A second translocation attempt was generally rejected because evidence indicated that adult Hawaiian forest birds have high site fidelity and usually return to their own home range following translocation (Fancy et al., 1997, 2001; Groombridge et al., 2004a), but birds might be more likely to remain together in a new location after forming a pair in captivity.

Both the US Fish and Wildlife Service and the Hawaii Department of Land and Natural Resources viewed the structured process by which this decision was reached as useful. From a biological standpoint, the decision tree and other evaluation tools provided a framework for presenting and considering a variety of information on a complex issue. From a regulatory standpoint, the decision tools helped create an explicit and transparent record of how and why the decision was made. Whether the decision tree and other materials helped group members reach their recommendation or whether it caused any members to change their mind is more difficult to determine. Some recommendations included well justified references to results of the decision tree. Other recommendations were not based on the decision tree at all, and seemed to have been preconceived. One recommendation attempted to use the decision tree for justification, but values entered into the tree lacked scientific support, suggesting they had been adjusted to match a desired outcome. 
In retrospect, several aspects of the decision tree exercise and the overall decision process could have been improved. First, asking members to give their estimates for the individual parameters first, before using them in the model, may have avoided the temptation to adjust estimates in order to fit a preconceived conclusion. Second, a sensitivity analysis could have been conducted to quantify the robustness of the overall rankings (Drechsler, 2000). Much as individuals were encouraged to conduct their own sensitivity analyses by varying the estimates of each parameter, an overall sensitivity analysis could have been done using the ranges of values given by participants. Third, there was some confusion among participants about how the various decision tools would be used. It was not the intention to use only the decision tree or any other method to the exclusion of others, but the presentation of multiple methods to a large group appeared to cause difficulty. The purpose of each method employed must be made clear at the outset, and methods should be kept as simple as practicable, especially if group members vary in analytic experience.

\section{Similar decisions and other species}

How does the decision to attempt removal and captive breeding of the Po'ouli compare to other cases where decision analysis has been applied to endangered species? Maguire et al. (1987) identified captive breeding as the most promising strategy for saving the Sumatran rhino (Dicerorhinus sumatrensis). However, ex situ measures failed to produce a viable captive-breeding program, and subsequent reflection indicated the causes of this species' decline, illegal poaching and habitat loss, had not been adequately addressed (Rabinowitz, 1995). For the California Condor (Gymnogyps californianus), a decision was made in 1981 to begin a captive breeding program (Maguire, 1986), and all remaining wild condors were captured by 1987 . Happily, the outcome has been more successful, with condors now restored to the wild in several areas and the first successful reproduction of released birds occurring in 2003 (US Fish and Wildlife Service, Hopper Mountain National Wildlife Refuge, California Condor website). For the Black-footed ferret (Mustela nigripes), the US Fish and Wildlife Service and the Wyoming Department of Game and Fish decided in 1985 to remove all known ferrets from the wild to save them from an outbreak of canine distemper. A successful captive breeding program was established, and ferrets have been reintroduced to four states (website of the Blackfooted ferret recovery program <<http://www.blackfootedferret.org $>>$ ).

It has been argued that captive breeding should be viewed only as a last resort in endangered species recovery efforts (Snyder et al., 1996), and that the "ark paradigm" is not a valid long-term recovery solution in most cases (Balmford et al., 1996). More recent simulations suggest captivity may be a critical measure for the persistence of small populations with less than 20 females (Tenhumberg et al., 2004). Few critically endangered birds have been recovered without intensive manipulation of the remaining individuals, although one outstanding example, the Rodrigues Fody (Foudia flavicans), was recovered from just 5-6 pairs in 1968 (Cheke, 1987) to 900 indi- viduals by 1999, as a direct consequence of 20 years of reforestation and ecosystem protection (Impey et al., 2002). It will be interesting to see whether managers are tempted to consider intensive methods such as captive-breeding to aid recovery of the recently rediscovered Ivory-billed Woodpecker, if more than one bird can be located.

The loss of a charismatic or flagship species to extinction or removal to captivity can lead to a perceived decrease in habitat value and thus funding for management (Caro and O'Doherty, 1999), and this concern was raised during discussions about the Po'ouli. Hanawi contains some of the finest native montane rainforest habitat in Hawaii and supports many rare plant and animal species. The Po'ouli Working Group, the US Fish and Wildlife Service, and the Hawaii Department of Land and Natural Resources maintain that every effort should be made to continue and to expand existing habitat management, regardless of whether Po'ouli are present.

The ultimate goal of the Po'ouli recovery program is to restore a self-sustaining wild population through release of captive-bred birds. Continued habitat protection and management is an essential component of the recovery effort in order to ensure that the threats responsible for the decline have been addressed and that suitable habitat is available for release of captive-bred Po'ouli. Continued habitat management also will benefit any wild Po'ouli that have not been located and are not part of captive propagation efforts. Much of the suitable habitat on east Maui has been surveyed (Reynolds and Snetsinger, 2001), but Po'ouli are difficult to detect and some areas have not been thoroughly searched, so it is difficult to say with certainty that no additional Po'ouli exist.

\section{Epilogue}

A protocol for capturing the remaining wild Po'ouli and transferring them to captivity was cooperatively designed and approved by the US Fish and Wildlife Service, Hawaii Department of Land and Natural Resources, and Zoological Society of San Diego in January 2003. Adverse weather and practical constraints hampered capture efforts, which began in February 2003, but on 9 September 2004, the first Po'ouli was captured and removed to captivity at the Maui Bird Conservation Center. Genetic sexing using a blood sample taken from the bird in captivity indicated it was a male. This result conflicted with earlier tests using DNA from feathers, and has cast some doubt on the sex of the two remaining birds, leading to the possibility that only one sex of Po'ouli remained. Even more remarkable, the captured bird was found to have only one functioning eye, the right eye had completely collapsed, probably as a result of a previous traumatic injury (K. Swinnerton, pers. obs.), and it had been infected with avian malaria before it was captured (C. Atkinson, pers. comm.). That the bird survived such physical challenges is testament to its toughness, and a reminder that it is the species that is endangered and not the individual.

Sadly, after being successfully maintained in captivity for 78 days, the captive Po'ouli died on 26 November 2004, before a potential mate could be obtained. The death of the captive bird was obviously a severe set back to the recovery of the 
species. Necropsy results revealed several chronic health problems, indicating the likely cause of death was old age (B. Rideout, pers. comm.). Although the bird had avian malaria, the infection was sub-clinical and was not the primary cause of death. Tissue samples were collected from the bird immediately following its death, and fibroblast cells were successfully grown and cryogenically preserved at the Zoological Society of San Diego's center for Conservation and Research for Endangered Species. The remaining two birds have not been seen since December 2003 and January 2004 (Maui Forest Bird Recovery Project, unpubl. data). If they are located, or if new birds are discovered, efforts to facilitate formation of a breeding pair will resume if possible.

For the Po'ouli, the decision to undertake captive propagation came too late, and it may be justifiably asked why this action was not undertaken earlier. Previous attempts at bringing adult Hawaiian forest birds into captivity indicated there was some risk of mortality and that the risk may vary among species (US Fish and Wildlife Service, Hawaii Department of Land and Natural Resources, 1999). Given the information available in 1999 on the potential for mortality in captivity and the lack of information on success of translocations, the decision to attempt a translocation appeared reasonable. Since then, methods of acclimating wild birds to captivity have been improved and more data has become available showing translocation of adults birds has a low success rate. The reluctance to undertake more invasive management actions may stem partly from a fear of risk and partly from fear of blame in case of failure. Lack of universal support for risky actions can increase the fear of blame, resulting in no action, which ultimately may incur the most risk of all. Perhaps the most important lesson from the case of the Po'ouli is that action must be taken early, before a time when a species' future rests on a single risky endeavor.

\section{Acknowledgements}

The Maui Forest Bird Recovery Project is jointly funded by the Hawaii Department of Land and Natural Resources and the US Fish and Wildlife Service. Permission to work in Hanawi and logistical assistance were provided by the Hawaii Natural Area Reserves System, and additional logistical support was provided by Haleakala National Park. We express our sincere gratitude to the following people and institutions: Alan Lieberman and Richard Switzer of the Zoological Society of San Diego for their assistance throughout this effort and their dedicated care of the captive Po'ouli; Bruce Rideout of the Zoological Society of San Diego for conducting the necropsy and providing veterinary guidance throughout the project; Ollie Ryder and staff of the Center for Conservation and Research for Endangered Species for growing and preserving Po'ouli tissue; and Carter Atkinson and Sue Jarvi of the US Geological Survey Biological Resources Division, Kilauea Field Station for conducting genetic tests of the sex of the captive bird and screening it for malaria. We thank all members of the Po'ouli Recovery Working Group for their dedication and participation in this process. The decision to bring the Po'ouli into captivity ultimately rested with the US Fish and Wildlife
Service and Hawaii Department of Land and Natural Resources, and does not necessarily indicate agreement by all group members.

\section{R E F E R E N C E S}

Baker, P.E., 2001. Status and distribution of the Po'ouli in the Hanawi Natural Area Reserve between December 1995 and June 1997. Studies in Avian Biology 22, 144-150.

Balmford, A., Mace, G.M., Leader-Williams, N., 1996. Designing the ark: setting priorities for captive breeding. Conservation Biology 10, 719-727.

Burgman, M.A., Ferson, S., Akcakaya, H.R., 1993. Risk Assessment in Conservation Biology. Chapman \& Hall, New York.

Caro, T.M., O'Doherty, G., 1999. On the use of surrogate species in conservation biology. Conservation Biology 13, 805-814.

Casey, T.L.C., Jacobi, J.D., 1974. A new genus and species of bird from the Island of Maui, Hawaii (Passeriformes: Drepanididae). Occasional Papers of the Bernice P. Bishop Museum 24, 216-226.

Cheke, A.S., 1987. Observations on the surviving endemic birds of Rodrigues. In: Diamond, A.W. (Ed.), Studies of Mascarene Island Birds. Cambridge University Press, pp. 364-402.

Drechsler, M., 2000. A model-based decision aid for species protection under uncertainty. Biological Conservation 94, 23-30.

Drechsler, M., Burgman, M.A., Menkhorst, P.W., 1998. Uncertainty in population dynamics and its consequences for the management of the Orange-bellied Parrot Neophema chrysogaster. Biological Conservation 84, 269-281.

Engilis Jr., A., Pratt, T.K., Kepler, C.B., Ecton, A.M., Fluetsch, M., 1996. Description of adults, eggshells, nestling, fledgling, and the nest of the Po'o-uli. Wilson Bulletin 108, 607-619.

Fancy, S.G., Snetsinger, T.J., Jacobi, J.D., 1997. Translocation of the Palila, an endangered Hawaiian honeycreeper. Pacific Conservation Biology 3, 39-46.

Fancy, S.G., Nelson, J.T., Harrity, P., Kuhn, J., Kuhn, M., Kuehler, C., Giffin, J.G., 2001. Reintroduction and translocation of 'Oma'o: a comparison of methods. Studies in Avian Biology 22, 347-353.

Fleischer, R.C., Tarr, C.L., James, H.F., Slikas, B., McIntosh, C.E., 2001. Phylogenetic placement of the Po'o-uli, Melamprosops phaeosoma, based on mitochondrial DNA sequence and osteological characters. Studies in Avian biology 22, 98-103.

Groombridge, J.J., Massey, J.G., Bruch, J.C., Malcolm, T.R., Brosius, C.N., Okada, M.M., Sparklin, B.D., 2004a. Evaluating stress in a Hawaiian honeycreeper (Paroreomyza montana) following translocation. Journal of Field Ornithology 75, 183-187.

Groombridge, J.J., Massey, J.G., Bruch, J.C., Malcolm, T.R., Brosius, C.N., Okada, M.M., Sparklin, B., Fretz, J.S., VanderWerf, E.A., 2004b. An attempt to recover the Po'ouli by translocation and an appraisal of recovery strategy for bird species of extreme rarity. Biological Conservation 118, 365-375.

Groombridge, J.J., Sparklin, B., Malcolm, T., Brosius, C.N., Okada, M.M., Bruch, J.C., in press. Patterns of spatial use and movement of the Po'ouli - a critically endangered Hawaiian honeycreeper. Biodiversity and Conservation.

Haight, R.G., Ralls, K., Starfield, A.M., 2000. Designing species translocation strategies when population growth and future funding are uncertain. Conservation Biology 14, 1298-1307.

Harwood, J., 2000. Risk assessment and decision analysis in conservation. Biological Conservation 95, 219-226.

Impey, A.J., Cote, I.M., Jones, C.G., 2002. Population recovery of the threatened endemic Rodrigues Fody (Foudia flavicans) (Aves, Ploceidae) following reforestation. Biological Conservation 107, 299-305. 
James, H.F., 2004. The osteology and phylogeny of the Hawaiian finch radiation (Fringillidae: Drepanidini), including extinct taxa. Zoological Journal of the Linnean Society 141, 207-255.

James, H.F., Olson, S.L., 1991. Descriptions of thirty-two new species of birds from the Hawaiian Islands. Part II. Passeriformes. Ornithological Monographs 46, 1-88.

Kepler, C.B., Pratt, T.K., Ecton, A.M., Englis, A., Fluetsch, M., 1996. Nesting behavior of the Po'o-uli. Wilson Bulletin 108, 620-638.

Kuehler, C., Lieberman, A., Oesterle, P., Powers, T., Kuhn, M., Kuhn, J., Nelson, J.T., Snetsinger, T., Herrman, C., Harrity, P., Tweed, E., Fancy, S., Woodworth, B., Telfer, T., 2000. Restoration techniques for Hawaiian thrushes: artificial incubation, hand-rearing, captive-breeding and reintroduction to the wild. Zoo Biology 19, 263-277.

Kuehler, C., Lieberman, A., Harrity, P., Kuhn, M., Kuhn, J., McIlraith, B., Turner, J., 2001. Restoration techniques for Hawaiian forest birds: collection of eggs, artificial incubation and hand-rearing of chicks, and release to the wild. Studies in Avian Biology 22, 354-358.

Lepson, J.K., Freed, L.A., 1997. Akepa (Loxops coccineus). In: Poole, A., Gill, F. (Eds.), The Birds of North America, 294. The Birds of North America, Inc., Philadelphia, PA.

Maguire, L.A, 1986. Using decision analysis to manage endangered species populations. Journal of Environmental Management 22, 345-360.

Maguire, L.A., Seal, U.S., Brussard, P.F., 1987. Managing critically endangered species: the Sumatran rhino as a case study. In: Soulé, M.E. (Ed.), Viable Populations for Conservation. Cambridge University Press, Cambridge, England, pp. 141-158.

Mountainspring, S., Casey, T.L.C., Kepler, C.B., Scott, J.M., 1990. Ecology, behavior, and conservation of the Po'o-uli (Melamprosops phaeosoma). Wilson Bulletin 102, 109-122.

Pratt, T.K., Kepler, C.B., Casey, T.L.C., 1997. Po'ouli (Melamprosops phaeosoma). In: Poole, A., Gill, F. (Eds.), The Birds of North America, vol. 272. The Birds of North America, Inc., Philadelphia, PA.

Rabinowitz, A., 1995. Helping a species go extinct: the Sumatran rhino in Borneo. Conservation Biology 9, 482-488.

Ralph, C.J., Fancy, S.G., 1996. Aspects of the life history and foraging ecology of the endangered Akiapola'au. Condor 98, 312-321.

Reynolds, M.H., Snetsinger, T.J., 2001. The Hawai'i Rare Bird Search 1994-1996. Studies in Avian Biology 22, 133-143.

Ryder, O.A., 2002. Cloning advances and challenges for conservation. Trends in Biotechnology 20, 231-232.
Scott, J.M., Mountainspring, S., Ramsey, F.L., Kepler, C.B., 1986. Forest bird communities of the Hawaiian islands: their dynamics, ecology, and conservation. Studies in Avian Biology 9, 1-431.

Simon, J.C., Pratt, T.K., Berlin, K.E., Kowalsky, J.R., 2000. Reproductive ecology of the Maui Parrotbill. Wilson Bulletin 112, 482-490.

Simon, J.C., Pratt, T.K., Berlin, K.E., Kowalsky, J.R., 2001. Reproductive ecology and demography of the 'Akohekohe. Condor 103, 736-745.

Snyder, N.F.R., Derrickson, S.R., Beissinger, S.R., Wiley, J.W., Smith, T.B., Toone, W.D., Miller, B., 1996. Limitations of captive breeding in endangered species recovery. Conservation Biology 10, 338-348.

Starfield, A.M., Bleloch, A.L., 1991. Building Models for Conservation and Wildlife Management. Interaction Book Company, Edina, Minnesota.

Stone, C.P., Stone, D.B., 1989. Conservation Biology in Hawai'i. Cooperative National Park Resources Studies Unit, University of Hawai'i, Manoa, Hawaii, USA.

Tenhumberg, B., Tyre, A.J., Shea, K., Possingham, H.P., 2004. Linking wild and captive populations to maximize species persistence: optimal translocation strategies. Conservation Biology 18, 1304-1314.

Thibodeau, F.F., 1983. Endangered species: deciding which species to save. Environmental Management 7, 101-107.

US Fish and Wildlife Service, Hawaii Department of Land and Natural Resources, 1999. Environmental Assessment: Proposed Management Actions to Save the Po'ouli, Melamprosops phaeosoma. US Fish and Wildlife Service and Hawai'i Department of Land and Natural Resources.

VanderWerf, E.A., 2003. Demography of Hawai'i 'Elepaio: variation with habitat disturbance and population density. Ecology 85 , 770-783.

VanderWerf, E.A., Smith, D.G., 2002. Effects of alien rodent control on demography of the O'ahu 'Elepaio, an endangered Hawaiian forest bird. Pacific Conservation Biology 8, 73-81.

van Riper III, C., Scott, J.M., 2001. Limiting factors affecting native Hawaiian birds. Studies in Avian Biology 22, 221-223.

Woodworth, B.L., Nelson, J.T., Tweed, E.J., Fancy, S.G., Moore, M.P., Cohen, E.B., Collins, M.S., 2001. Breeding productivity and survival of the endangered Hawaici creeper in a wet forest refuge on Mauna Kea, Hawai'i. Studies in Avian Biology 22, 164-172. 